\title{
Truth relative to aortic overriding
}

Keywords: Tetralogy of Fallot; aortic dextroposition; ventricular septal defect

Received: 16 May 2013; Accepted: 16 June 2013; First published online: 9 September 2013

Sir,

"Truth and aortic overriding".

When I read the title of the article published in the June issue entitled "Tips and pearls for 'true' dextroposition of the aorta in tetralogy of Fallot", I was reminded of the controversy surrounding the quotation over the use of the word "culture". As explained in Wikipedia, the suggestion that hearing the word "culture" prompts the reach for one's revolver has been dedicated to various members of the Nazi hierarchy during the second World War. The quotation is from the play "Schlageter" by Hanns Johst and is better translated as "When I hear the word culture..., I release the safety on my Browning!" I have this very response, nonetheless, when I see the word "true" used in reference to aortic dextroposition and tetralogy of Fallot. I wonder who has revealed the secret of universal truth to Bozok et al? ${ }^{1}$ Their abrogation of this quality to themselves is more remarkable when they suggest that only four of ten possible illustrations in the textbook edited by myself and my colleagues illustrate "true dextroposition of the aorta". The first remarkable aspect of their interpretation is that they choose to cite the first edition of a work that now appears in its third edition. The second remarkable aspect is that they ignore completely the statement made in the first edition that "the precise degree of aortic override can vary between $5 \%$ and $95 \%$ of the valve being connected to the right ventricle". 2 This statement in itself should have made clear to the authors that my colleagues and I describe "aortic override" as opposed to "dextroposition". As we also stated in the introduction to the cited paragraph "Because the normal aortic valve overrides a good part of the ventricular septum, there has been some question as to whether the aortic overriding in tetralogy is more apparent

Correspondence to: Robert H. Anderson, 60 Earlsfield Road, London SW 18 3DN, United Kingdom. Tel: 020-8870-4368; E-mail: sejjran@ucl.ac.uk than real". ${ }^{2}$ In our third edition, we then qualify this earlier remark, having realised its potential ambiguity. Thus, in our latest version we explain that "in the normal heart, although the right aortic sinus of the aortic valve overrides spatially the crest of the muscular ventricular septum, the leaflets of the aortic valve are attached exclusively within the left ventricle". ${ }^{3}$ It is the realisation of this fact that should clarify our approach towards aortic overriding. I would now suggest that aortic overriding be defined only when ventricular septation is deficient and there is potential for biventricular connection of the aortic valve. It was this particular feature, namely biventricular connection of the aortic valve, that was described by Fallot when offering his initial account of the entity we now name in his honour. ${ }^{4}$ If we had continued to use this description, rather than "aortic dextroposition", then we could have avoided the specious argumentations as put forward by Bozok et al. ${ }^{1}$ Moreover, we should remember that the plane of space nominated by Bozok and colleagues as the "ventricular septal defect" in their Figure 3 is better described as interventricular communication. This is because the place of deficient ventricular septation extends to the undersurface of the deviated muscular outlet septum, which in tetralogy of Fallot is exclusively a right ventricular structure. This important distinction is also emphasised in the third edition of our textbook, being illustrated in Figure 36.10. ${ }^{3}$ Unlike Bozok and colleagues, however, we made no claim for the "truth" of our suggestions. I would simply comment that they are substantiated by the images shown in the specific chapters of our textbooks, which is more than can be said for the questionable assertions of Bozok et al. ${ }^{1}$

Yours faithfully,

Robert H. Anderson Institute of Medical Genetics Newcastle University Newcastle-upon-Tyne United Kingdom 


\section{References}

1. Bozok S, Kestelli M, Ilhan G, et al. Tips and pearls for "true" dextroposition of the aorta in tetralogy of Fallot. Cardiol Young 2013; 23: 377-380.

2. Anderson RH, Macartney FJ, Shinebourne EA, Tynan M (eds). Fallot's tetralogy. In: Paediatric Cardiology, Vol 2. Churchill Livingstone, Edinburgh, 1987: 771.

3. Anderson RH, Baker EJ, Penny DJ, Redington AN, Rigby ML, Wernovsky G (eds). In: Paediatric Cardiology, 3rd edn. Churchill Livingstone/Elsevier, Philadelphia, USA, 2010: 757, 759.

4. Fallot A. Contribution a l'anatomie pathologique de la maladie bleue (cyanose cardiague). Mars Med 1888; 25: 77-403. 